\title{
Autoimmune comorbidities in patients with metastatic melanoma: a retrospective analysis of us claims data
}

\author{
Qiufei Ma ${ }^{1}$, Mark Shilkrut ${ }^{2}$, Zhongyun Zhao ${ }^{1 *}$, Minming $\mathrm{Li}^{3}$, Nicolas Batty ${ }^{2}$ and Beth Barber ${ }^{1}$
}

\begin{abstract}
Background: Immunotherapies have advanced the treatment of metastatic melanoma; however, they are associated with immune-related toxicities. Patients with pre-existing autoimmune comorbidities are commonly excluded from clinical trials investigating immunotherapies in metastatic melanoma. Since information on preexisting autoimmune comorbidities in "real-world" patients with newly diagnosed metastatic melanoma is limited, we sought to estimate the prevalence of autoimmune comorbidities and its change over time.

Methods: Data were obtained from a large US claims database, MarketScan ${ }^{\oplus}$, from 2004 to 2014. Records of patients with newly diagnosed metastatic or non-metastatic melanoma and of general population were analyzed. Autoimmune comorbidities were defined as presence of autoimmune disorders, which were obtained from the list of diseases at the American Autoimmune-Related Diseases Association web portal (www.aarda.org). The prevalence of pre-existing autoimmune comorbidities and its change over the 11-year period were calculated. Logistic regression analyses were performed to evaluate the relationship between clinical and demographic factors and pre-existing autoimmune comorbidities in patients with metastatic melanoma.
\end{abstract}

Results: This study assessed the prevalence and change of prevalence over a period of 11 years of 147 autoimmune comorbidities. Among 12,028 patients with newly diagnosed metastatic melanoma, the prevalence rate of pre-existing autoimmune comorbidities increased from 17.1\% in 2004 to 28.3\% in $2014(P<0.001)$. The prevalence rates of autoimmune comorbidities increased from 11.7\% in 2004 to 19.8\% in 2014 in patients with non-metastatic melanoma and $7.9 \%$ in 2004 to $9.2 \%$ in 2014 in the general population. In addition, patients with bone or gastrointestinal melanoma metastases, those with more comorbid diseases, or female patients, were found to have a higher risk of autoimmune comorbidities.

Conclusions: The prevalence of pre-existing autoimmune comorbidities in patients with newly diagnosed metastatic melanoma was high, and increased over 11 years. In comparison, a lower prevalence of autoimmune comorbidities was seen in patients with newly diagnosed non-metastatic melanoma and in the general population. Increases in prevalence for these population groups were also observed over 11 years. Impact of autoimmune comorbidities on treatment decisions in patients with metastatic melanoma should be explored.

Keywords: Autoimmune, Comorbidities, Metastatic melanoma, Retrospective analysis, Prevalence rate

\footnotetext{
* Correspondence: zhongyun@amgen.com

'Department of Global Health Economics, Amgen Inc., One Amgen Center

Drive, Thousand Oaks, CA 91320-1799, USA

Full list of author information is available at the end of the article
} 


\section{Background}

More than 73,000 new cases of melanoma were expected to be diagnosed in 2015. This represents less than $2 \%$ of all new skin cancer cases; however, such cases are responsible for $90 \%$ of skin cancer-related deaths $[1,2]$.

Treatment guidelines for melanoma reflect both the biological characteristics of the tumor and the stage at which it is detected. If discovered early, excision represents the standard of care for early-stage melanoma [3]. Surgical removal is also recommended for loco-regional recurrences of melanoma. For distant metastases, surgery may also be considered if the disease is site- and volume-limited and is technically resectable; however, for unresectable metastatic disease current guidelines recommend: systemic therapy, clinical trial, intralesional injection, or best supportive care (recommendations differ for different stages, biological characteristics of the tumor, performance status of the patient etc.) [3].

US cancer statistics show 5-year relative survival rate for localized melanoma ( $84 \%$ of cases) of $98 \%$; however, survival declines to $63 \%$ and $16 \%$ for regional and distant-stage disease, respectively [1]. Real-world data from patients with metastatic melanoma have shown great variation in survival time according to disease stage of the melanoma [4]. In a study of patients with metastatic melanoma from the Surveillance, Epidemiology, and End Results database [5], the median overall survival time (time between the date of randomization and the date of death) was longer in patients diagnosed with unresectable non-visceral (stage IIIB/C or IVM1a) metastatic melanoma (22.3-24.3 months) than in patients diagnosed with visceral unresectable stage IVM1b or IVM1c metastatic melanoma (5.1-11.2 months) [5].

Prior to 2011, some improvement in response rates were observed with systemic biochemotherapy (cytokine-based immunotherapy in combination with cytotoxic chemotherapy) [6-8]. However, treatment options for metastatic melanoma prior to 2011 offered little hope for patients with metastatic melanoma as none of the available options had demonstrated an effect on overall survival. Advances in the development of cancer immunotherapies included insights into the mechanisms used by cancer cells to subvert the antitumor immune response, including the production of inhibitory cytokines, recruitment of immunosuppressive immune cells and the upregulation of co-inhibitory receptors known as immune checkpoints [9]. As a result, some success has been achieved using immunotherapies targeting cancer-associated immunosuppression; notably, the use of immune checkpoint inhibitors [9]. These findings, in addition to the discovery of melanoma driver mutation subsets and the important role that the mitogen-activated protein kinase pathway plays in a significant part of melanomas [10], have led to the approval of nine new treatments or combinations thereof since $2011[3,9,11]$.

Among the treatments approved since 2011, B-Raf proto-oncogene, serine/threonine kinase and mitogenactivated protein kinase 1 inhibitors target abnormally activated protein kinases [11], whereas immune checkpoint inhibitors act by enhancing T-lymphocyte function. Regulatory approved immune checkpoint inhibitors include ipilimumab, pembrolizumab, and nivolumab, while molecularly targeted drugs approved at this time include vemurafenib, dabrafenib and trametinib and cobimetinib, used as single agents (first three) or in combination.

The use of immune checkpoint inhibition has led to significant improvements in some clinical outcomes for patients with metastatic melanoma, giving rise to approvals of ipilimumab, nivolumab, and pembrolizumab as single agents in this setting. Current clinical trials focus on the combination of immune checkpoint inhibitors with each other, or with targeted therapies. However; to date, the optimal sequence and combination of targeted drugs and immunotherapies are still unknown [11].

There are limitations to the use of immunotherapy, with immune-related adverse events (AEs) associated with these treatments $[12,13]$. Ipilimumab therapy has been associated with distinctive immune-related AEs, including colitis, dermatitis, hepatitis, endocrinopathies and neuropathies, all of which may be attributed to an inflammatory effect of non-specific lymphocyte activation [11]. Of patients treated with ipilimumab, 10\%-15\% have been shown to experience immune-related AEs of grade 3 or higher [11]. In a phase 3 study assessing ipilimumab as adjuvant therapy for patients with completely resected stage III melanoma [14], five patients died due to ipilimumab-related AEs. Results from a phase 2 study of pembrolizumab in advanced melanoma reported a less common incidence of immune-mediated AEs and of lesser severity [15]. These immune AEs occur despite clinical trial protocols that exclude patients with preexisting autoimmune comorbidities.

The approval label for immune checkpoint inhibitors reflects the potential occurrence of immune-related AEs with these agents; the US Food and Drug Administration Prescribing Information and European Medicines Agency Summary of Product Characteristics for ipilimumab, nivolumab and pembrolizumab carry warnings that these agents are associated with immune-related AEs [16-21]. Patient information brochures inform recipients of these risks; in addition, risk management plans have been developed for these agents to ensure that they are used as safely as possible [22-24].

Patients with active, known or suspected autoimmune disorders were thought to be at greater risk of developing immune-mediated AEs and would therefore not be 
good candidates for inclusion in clinical studies of immune checkpoint inhibitors; they were excluded from the pivotal randomized controlled trials of these treatments [25-27]. Hence, the clinical data do not provide an overall indication of the prevalence of autoimmune disorders within the population of patients with metastatic melanoma nor the extent of the patient population for whom immune-related AEs represent a barrier to the use of immune checkpoint inhibition.

Additionally, limited information is available as to the prevalence of patients with metastatic melanoma who also have pre-existing autoimmune disorders. This study therefore aims to assess the prevalence of autoimmune disorders and time trend over a period of 11 years from 2004 to 2014 primarily in patients with metastatic melanoma.

\section{Methods}

\section{Study design and data source}

This is a US population-based retrospective study using claims data from the Truven MarketScan ${ }^{\oplus}$ database. This database contains information on approximately 30 million people with employer-sponsored primary or Medicare supplemental insurance. The database includes dates of enrollment in the insurance program, inpatient and outpatient visits, and prescription drugs dispensed. Demographic data include sex, age, and region. All claims were coded with International Classification of Diseases, Ninth Edition (ICD-9), codes [28].

\section{Study measures}

A list of autoimmune disorders assessed in this study were obtained from the site of the American Autoimmune-Related Diseases Association (www.aarda.org). All 147 autoimmune conditions posted at their site were included [29]. For each condition, corresponding ICD-9-CM codes were used to identify the condition in the Truven MarketScan ${ }^{\oplus}$ database.

The following covariates for the prevalence of autoimmune comorbidities were evaluated for the patients with metastatic melanoma: demographic factors (age, gender and geographical region), metastatic site, Charlson Comorbidity Score (a weighted score of 16 pre-existing diseases, excluding cancers) and Category (whether the score is 0,1 , or $>=2$ ), and health insurance plan, including being a Medicare beneficiary.

\section{Study populations}

Records between July 1, 2003 and June 30, 2014 were obtained from the Truven MarketScan ${ }^{\circ}$ Commercial and Medicare database. Three population groups were defined for analysis.

The first group were patients with metastatic melanoma with at least one inpatient or outpatient melanoma diagnosis (ICD-9-CM: 172.xx, V10.82) and at least one inpatient or outpatient metastatic diagnosis (ICD-9-CM: 196.xx-198.xx). The first metastasis diagnosis date should be less than 30 days before, or any time after, the melanoma diagnosis. The index date was the first date of metastasis diagnosis. An autoimmune comorbidity was indicated as "present" for a given patient if any of the autoimmune conditions codes were detected during the 12 months prior to or on the index date.

The second patient group comprised those with non-metastatic melanoma. The index date was the first date of melanoma diagnosis and those patients who subsequently developed metastases were excluded. An autoimmune comorbidity was indicated as "present" if any of the autoimmune conditions codes were detected during the 12 months prior to or on the index date.

Of note, patients with metastatic melanoma or nonmetastatic melanoma were required to be continuously enrolled in the health plan for at least 1 year prior to the index date. Please also note that each patient could only appear once in the metastatic melanoma or nonmetastatic melanoma cohort.

Lastly, a general population group included all people in the database who were beneficiaries between January 1, 2004, and June 30, 2014. For each year, autoimmune comorbidity was defined as one or more of the 147 autoimmune conditions occurring within that year.

\section{Statistical analysis}

Descriptive analyses were conducted to estimate the prevalence of autoimmune comorbidities within each of the three populations described. The trend in prevalence over a period of 11 years from 2004 to 2014 was assessed.

Clinical and demographic characteristics were compared between patients with metastatic melanoma who had autoimmune comorbidities and those who did not have. T-tests were performed for continuous variables and a chi-square test for categorical variables. Logistic regression analysis was conducted to determine if a statistically significant change had occurred for the prevalence of autoimmune comorbidities among patients with metastatic melanoma. Multivariate logistic regressions were used to examine the impact of covariates on autoimmune comorbidities in patients with metastatic melanoma. Odds ratios (ORs) with 95\% confidence intervals (CIs) were presented.

All data were extracted and analyzed using programs organized within $\mathrm{SAS}^{\odot}$ Enterprise Guide version 4.2 (SAS Institute Inc., Cary, NC, USA) and conducted under UNIX using SAS version 9.2. All statistical tests were 2 -sided. 


\section{Results}

\section{Common Autoimmune comorbidities}

Among 147 autoimmune conditions that were assessed in patients with metastatic melanoma, the ten most prevalent are shown in Table 1.

\section{Characteristics in patients with metastatic melanoma}

A total of 12,028 patients with newly diagnosed metastatic melanoma were identified in the database: 2980 had autoimmune comorbidities and 9048 did not have autoimmune comorbidities. Demographic and clinical characteristics of these two groups of patients are shown in Table 2.

The distribution of age, gender, health plan type, Medicare beneficiaries, metastatic site, and Charlson Comorbidity Index score or category were different between the individuals with autoimmune comorbidities versus those without autoimmune comorbidities. Individuals with autoimmune comorbidities had a higher proportion of females, a higher proportion of individuals older than 65, and a higher mean Charlson comorbidity score.

\section{Prevalence trends of Autoimmune comorbidities between 2004 and 2014}

Among 12,028 patients with newly diagnosed metastatic melanoma, the prevalence rate of autoimmune comorbidities increased 1.7-fold: from $17.1 \%$ in 2004 to $28.3 \%$ in 2014, and the time trend was statistically significant $(P<0.001)$ based on a trend analysis using a GENMOD regression using the whole data.

The prevalence rates of autoimmune comorbidities were lower in patients with non-metastatic melanoma
(11.7\% in 2004 to $19.8 \%$ in 2014 ) and in the general population (7.9\% in 2004 to $9.2 \%$ in 2014 ), but the rates increased 1.7- and 1.2-fold over time, respectively (Fig. 1; Table 3).

\section{Factors influencing autoimmune comorbidities for patients with metastatic melanoma}

Multivariate logistic regression analysis of covariates/factors for prevalence of autoimmune comorbidities in patients with metastatic melanoma is shown in Table 4. Patients were more likely to have autoimmune comorbidities if they were females (vs. males; OR $=1.42 ; 95 \%$ CI: 1.30-1.55), had bone metastasis (vs. skin metastases, $\mathrm{OR}=1.77 ; 95 \% \mathrm{CI}:$ 1.37-2.29), had gastrointestinal metastases (vs. skin metastases, $\mathrm{OR}=1.64 ; 95 \% \mathrm{CI}$ : 1.19-2.27), or had a higher Charlson comorbidity score (vs. score being zero, $\mathrm{OR}=3.37$; 95\% CI: 2.99-3.80).

\section{Sensitivity analyses}

Sensitivity analyses were carried out in patients with metastatic renal-cell carcinoma (RCC) and metastatic breast cancer, respectively. Prevalence rates of autoimmune comorbidities increased from $18.5 \%$ to $28.3 \%$ for RCC and from $17.7 \%$ to $24.2 \%$ for metastatic breast cancer between 2004 and 2014. The increase in prevalence of autoimmune disease in patients with metastatic melanoma (from $17.1 \%$ to $28.3 \%$; 2004-2014) is similar to that found for patients with RCC. On the other hand, metastatic breast cancer has slightly lower prevalence of autoimmune diseases and extent at which their occurrence increased over the study duration in patients with this tumor type compared with patients with melanoma.

Table 1 The ten most prevalent autoimmune conditions in individuals with metastatic melanoma

\begin{tabular}{|c|c|c|c|c|c|}
\hline No. & Autoimmune conditions & ICD-9 codes & $\begin{array}{l}\% \text { in metastatic } \\
\text { melanoma } \\
(N=12,028)\end{array}$ & $\begin{array}{l}\% \text { in non-metastatic } \\
\text { melanoma } \\
(N=127,184)\end{array}$ & $\begin{array}{l}\% \text { in general } \\
\text { population } \\
(N=342,492,007)\end{array}$ \\
\hline 1 & Myositis & 729.1 & 3.6 & 3.1 & 2.2 \\
\hline 2 & Peripheral neuropathy & $356.0,356.8,356.9$ & 2.6 & 1.5 & 0.5 \\
\hline 3 & Type 1 diabetes mellitus & $250 . \times 1,250 . \times 3$ & 2.4 & 1.6 & 1.1 \\
\hline 4 & Rheumatoid arthritis & $\begin{array}{l}\text { 714, 714.0, 714.1, 714.2, 714.3, } \\
\text { 714.31, 714.32, 714.33, 714.4, } \\
\text { 714.8, 714.81, 714.89, } 714.9\end{array}$ & 1.7 & 1.4 & 0.8 \\
\hline 5 & Psoriasis & $\begin{array}{l}696,696.0,696.1,696.2,696.3 \\
696.4,696.5,696.8\end{array}$ & 1.1 & 1.5 & 0.8 \\
\hline 6 & Autoimmune pancreatitis & $577.0,577.1$ & 1.1 & 0.3 & 0.2 \\
\hline 7 & Autoimmune aplastic anemia & $284,284.89,284.9$ & 1.0 & 0.1 & $<0.1$ \\
\hline 8 & Relapsing polychondritis & 733.99 & 0.9 & 0.3 & 0.2 \\
\hline 9 & Hashimoto's encephalitis & 348.30 & 0.9 & 0.2 & 0.2 \\
\hline 10 & Ulcerative colitis & $\begin{array}{l}556,556.0,556.1,556.2,556.3 \\
556.4,556.5,556.6,556.8,556.9\end{array}$ & 0.7 & 0.5 & 0.3 \\
\hline
\end{tabular}


Table 2 Demographic and clinical characteristics of individuals with metastatic melanoma

\begin{tabular}{|c|c|c|c|c|}
\hline & Total $(N=12,028)$ & Without autoimmune conditions ( $n=9048)$ & With autoimmune conditions $(n=2980)$ & $P$-value \\
\hline Age, mean (SD) ${ }^{\mathrm{a}}$ & $64.2(14.2)$ & $63.9(14.4)$ & $65.2(13.6)$ & $<0.0001$ \\
\hline \multicolumn{4}{|l|}{ Age group, $\mathrm{n}(\%)^{\mathrm{a}}$} & $<0.0001$ \\
\hline $18-34$ & $289(2.4)$ & $235(2.6)$ & $54(1.8)$ & \\
\hline $35-54$ & $2614(21.7)$ & $2049(22.7)$ & $565(19.0)$ & \\
\hline $55-64$ & $3553(29.5)$ & $2651(29.3)$ & $902(30.3)$ & \\
\hline $65-74$ & $2304(19.2)$ & $1681(18.6)$ & $623(20.9)$ & \\
\hline$\geq 75$ & $3268(27.2)$ & $2432(26.9)$ & $836(28.1)$ & \\
\hline \multicolumn{4}{|l|}{ Gender, n (\%) ${ }^{\mathrm{a}}$} & $<0.0001$ \\
\hline Male & $7574(63.0)$ & $5824(64.4)$ & $1750(58.7)$ & \\
\hline Female & $4454(37.0)$ & $3224(35.6)$ & $1230(41.3)$ & \\
\hline \multicolumn{4}{|l|}{ Health insurance plan, $\mathrm{n}(\%)^{\mathrm{a}}$} & 0.042 \\
\hline Comprehensive & $2799(23.3)$ & $2109(23.3)$ & $690(23.2)$ & \\
\hline $\mathrm{HMO}$ & 1429 (11.9) & $1120(12.4)$ & $309(10.4)$ & \\
\hline POS & $578(4.8)$ & $438(4.8)$ & $140(4.7)$ & \\
\hline PPO & $6058(50.4)$ & $4520(50.0)$ & $1538(51.6)$ & \\
\hline Others & $1164(9.7)$ & $861(9.5)$ & $303(10.2)$ & \\
\hline \multicolumn{4}{|l|}{ Medicare beneficiaries, n (\%) } & 0.007 \\
\hline Yes & 5517 (45.9) & $4086(45.2)$ & $1431(48.0)$ & \\
\hline No & $6511(54.1)$ & $4962(54.8)$ & $1549(52.0)$ & \\
\hline \multicolumn{4}{|l|}{ Regions, n (\%) } & 0.109 \\
\hline North East & $1760(14.6)$ & $1296(14.3)$ & $464(15.6)$ & \\
\hline North Central & 3065 (25.5) & $2320(25.6)$ & $745(25.0)$ & \\
\hline South & 4165 (34.6) & $3180(35.2)$ & $985(33.1)$ & \\
\hline West & $2549(21.2)$ & $1888(20.9)$ & $661(22.2)$ & \\
\hline Unknown/Other & $489(4.1)$ & $364(4.0)$ & $125(4.2)$ & \\
\hline \multicolumn{4}{|l|}{ Metastasis site, $\mathrm{n}(\%)^{\mathrm{a}}$} & $<0.0001$ \\
\hline Brain & $2082(17.3)$ & $1551(17.1)$ & $531(17.8)$ & \\
\hline Bone & $1541(12.8)$ & $1044(11.5)$ & $497(16.7)$ & \\
\hline Liver & $1109(9.2)$ & $814(9.0)$ & $295(9.9)$ & \\
\hline Gastro-intestinal system & $386(3.2)$ & $269(3.0)$ & $117(3.9)$ & \\
\hline Lungs & $1372(11.4)$ & $1042(11.5)$ & $330(11.1)$ & \\
\hline \multicolumn{4}{|c|}{ Charlson comorbidity score, mean (SD) } & $<0.0001$ \\
\hline & $0.6(1.0)$ & $0.5(0.9)$ & $0.9(1.3)$ & \\
\hline \multicolumn{4}{|l|}{ Charlson Category, N (\%) ${ }^{a}$} & $<0.0001$ \\
\hline 0 & $8038(66.8)$ & $6477(71.6)$ & $1561(52.4)$ & \\
\hline 1 & $2430(20.2)$ & $1687(18.7)$ & $743(24.9)$ & \\
\hline$\geq 2$ & $1560(13.0)$ & $884(9.8)$ & $676(22.7)$ & \\
\hline
\end{tabular}

HMO health maintenance organization, POS point of service plan, PPO preferred provider organization, SD standard deviation ${ }^{a}$ indicates statistically significant at $5 \%$

\section{Discussion}

More recently approved treatments for metastatic melanoma, such as immune checkpoint inhibitors, have been shown to be associated with immune-related AEs. Therefore, pivotal clinical studies undertaken with these agents excluded patients with immune-related disorders.
This study estimated the prevalence of immune-related comorbidities in patients with metastatic melanoma using existing claims data gathered between January 1 , 2004 and June 30, 2014.

The study analyzed three patient populations: patients with newly metastatic melanoma, patients with non- 


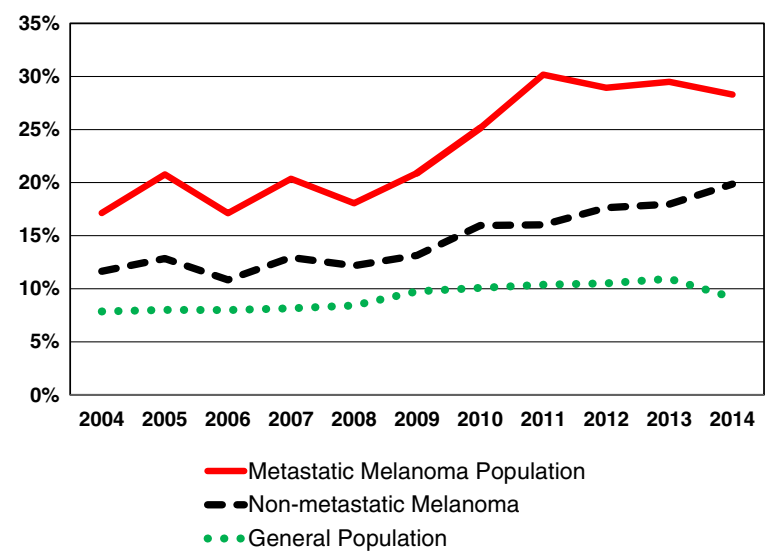

Fig. 1 One-year prevalence of autoimmune comorbidities in individuals with metastatic melanoma, non-metastatic melanoma, and in the general population, from 2004 to 2014

metastatic melanoma, and the general population. Over the study period the prevalence of autoimmune comorbidities in all three patient groups increased over time from 2004 to 2014. The prevalence of autoimmune comorbidities in patients with metastatic melanoma is higher than that in patients with non-metastatic melanoma, and the prevalence in both these patient groups is higher than that for the general population. The prevalence of autoimmune disease in the general population in this study of $7.9-9.2 \%$ was broadly consistent with existing data on the prevalence of autoimmune disorders in the general population: (7.6 to $9.4 \%$, depending on the size of the correction factor used) [30-32].

Sensitivity analyses were conducted to explore the prevalence of autoimmune comorbidities in RCC and in

Table 3 Total yearly patient numbers derived from the database

\begin{tabular}{llll}
\hline Year & $\begin{array}{l}\text { Metastatic melanoma } \\
\text { population }\end{array}$ & $\begin{array}{l}\text { Non-metastatic } \\
\text { melanoma population }\end{array}$ & $\begin{array}{l}\text { General } \\
\text { population }\end{array}$ \\
\hline 2004 & 496 & 5526 & $19,126,506$ \\
2005 & 756 & 7278 & $21,519,205$ \\
2006 & 590 & 5906 & $23,368,796$ \\
2007 & 889 & 8210 & $23,494,037$ \\
2008 & 1047 & 10,738 & $28,532,791$ \\
2009 & 1325 & 16,101 & $33,672,641$ \\
2010 & 883 & 12,333 & $37,437,295$ \\
2011 & 1515 & 18,493 & $44,028,795$ \\
2012 & 1828 & 20,660 & $44,745,958$ \\
2013 & 1522 & 17,784 & $37,307,087$ \\
2014 & 1177 & 4155 & $29,258,896$ \\
Total & 12,028 & 127,184 & $342,492,007$ \\
\hline
\end{tabular}

metastatic breast cancer. The findings in RCC, another cancer that has been considered responsive to immune therapy and associated with autoimmune disorders [33], were consistent with that in metastatic melanoma; while the prevalence and increase over time in metastatic breast cancer were slightly lower than that in metastatic melanoma.

Reasons for the increase in prevalence of autoimmune comorbidities observed in patients with metastatic melanoma compared with patients with melanoma or the general population could include paraneoplastic effects of melanoma on the immune system. In addition, this increase could be due to increased awareness and better diagnosis of immune disorders over the time frame of the study. However, one cannot exclude the possibility that disturbances in shared genetic or immune pathways could lead to increased susceptibility to develop neoplasms in patients afflicted by autoimmune conditions. Additionally, potential use of immunosuppressive drug therapy before or after metastatic melanoma might also result in the increase in auto-immune disease. However, the use of immunosuppressive drug therapy before metastatic melanoma diagnosis was very limited as most patients with in situ or early melanoma will be cured by primary excision alone; and the newer immunotherapies for metastatic melanoma were approved for use only after 2011 (one drug) and 2014 (two drugs).

Knowledge of the likelihood of developing autoimmune disorders or immune-related AEs has implications when choosing treatments for patients and allows greater individualization of treatment. As immunomodulatory treatments such as immune checkpoint inhibitors exert their effects via the immune system, knowledge that patients have comorbid autoimmune disorders could be used to assess their suitability for treatment with such drug classes.

This study also conducted multivariate logistic regression analyses to examine factors for influencing the prevalence of autoimmune comorbidities within the population of patients with metastatic melanoma. This analysis showed that in patients with metastatic melanoma, those who were female, located in South or North Central US regions, had bone or gastrointestinal metastasis, or a high comorbid disease burden (indicated by their Charlson Comorbidity Index), were more likely to have autoimmune comorbidities. These indicated additional factors, which could be taken into account when deciding upon an individual's course of treatment for metastatic melanoma and their risks of autoimmune comorbidities; and hence whether this would influence the choice of a drug class that acts via the immune system.

Data for this study were taken from an existing database. A limitation of the study is that the data were 
Table 4 Multivariate logistic regression of factors for autoimmune comorbidities in individuals with metastatic melanoma

\begin{tabular}{|c|c|c|c|c|}
\hline & \multirow[t]{2}{*}{ Odds ratio } & \multicolumn{2}{|c|}{ 95\% confidence interval } & \multirow[t]{2}{*}{$P$-value } \\
\hline & & Lower & Upper & \\
\hline \multicolumn{5}{|l|}{ Age group (Reference: 55-64) } \\
\hline $18-34$ & 0.83 & 0.61 & 1.14 & 0.25 \\
\hline $35-54$ & 0.90 & 0.79 & 1.02 & 0.09 \\
\hline $65-74$ & 1.09 & 0.87 & 1.37 & 0.46 \\
\hline$\geq 75$ & 0.92 & 0.72 & 1.17 & 0.48 \\
\hline Female $^{a}$ (Reference: Male) & 1.42 & 1.30 & 1.55 & $<0.001$ \\
\hline \multicolumn{5}{|l|}{ Health Insurance Plan (Reference: Others) } \\
\hline Comprehensive & 0.84 & 0.70 & 1.00 & 0.06 \\
\hline $\mathrm{HMO}^{\mathrm{a}}$ & 0.75 & 0.62 & 0.90 & 0.01 \\
\hline POS & 0.92 & 0.72 & 1.17 & 0.51 \\
\hline PPO & 0.98 & 0.85 & 1.14 & 0.83 \\
\hline Medicare beneficiaries (Reference: No Medicare) & 0.94 & 0.75 & 1.19 & 0.62 \\
\hline \multicolumn{5}{|l|}{ Regions (Reference: West) } \\
\hline North East & 0.96 & 0.83 & 1.11 & 0.57 \\
\hline North Central ${ }^{a}$ & 0.88 & 0.78 & 0.99 & 0.04 \\
\hline South $^{a}$ & 0.86 & 0.76 & 0.96 & 0.01 \\
\hline \multicolumn{5}{|l|}{ Metastasis site at index (Reference: Skin) } \\
\hline Brain & 1.22 & 0.95 & 1.57 & 0.12 \\
\hline Bone $^{a}$ & 1.77 & 1.37 & 2.29 & $<0.001$ \\
\hline Liver & 1.30 & 1.00 & 1.71 & 0.05 \\
\hline Gastrointestinal $^{a}$ & 1.64 & 1.19 & 2.27 & 0.01 \\
\hline Lung & 1.19 & 0.91 & 1.55 & 0.20 \\
\hline \multicolumn{5}{|l|}{ Charlson Category (Reference: 0) } \\
\hline $1^{\mathrm{a}}$ & 1.88 & 1.69 & 2.09 & $<0.001$ \\
\hline$\geq 2^{a}$ & 3.37 & 2.99 & 3.80 & $<0.001$ \\
\hline
\end{tabular}

$H M O$ health maintenance organization, $P O S$ point of service plan, $P P O$ preferred provider organization

${ }^{a}$ Indicates statistically significant at $5 \%$

derived from patients with commercial insurance; therefore, the results may not be representative of all patients, especially those uninsured or covered by Medicaid. ICD-9 codes used to identify metastatic may include metastases due to primary malignant neoplasms other than melanoma. Therefore those metastatic melanoma patients might have other malignant neoplasms. ICD-9 codes for several autoimmune conditions (e.g. Castleman's disease) explored are not available; and only 12-month prior history was examined for these lifelong autoimmune conditions. Therefore, the true prevalence of autoimmune comorbidities in this study may be underestimated. Additionally, only half year data was available for 2003 and 2014, the prevalence rates of autoimmune diseases for patients with metastatic melanoma or with non-metastatic melanoma might be underestimated for 2004, while the prevalence rate for general population could be underestimated for
2014. Finally, the prevalence estimates are based on diagnoses reported in the claims and hence may also be an underestimate of the true prevalence.

This study has some strengths. This is the first study, to our best knowledge, that examined the prevalence of autoimmune diseases in patients with metastatic melanoma, which is important as newer treatment options for metastatic melanoma, such as checkpoint inhibitors, could induce or worsen autoimmune conditions. The database used for this study contains over 30 million distinct individuals (over 342 million patient-years) and patients enrolled in this database have a similar overall age distribution to the nationally representative population in Medical Expenditure Panel Survey. Finally, sensitivity analyses of prevalence of autoimmune diseases in patients with RCC and metastatic breast cancer provided consistent results as observed in melanoma populations. 


\section{Conclusions}

The results of this study showed that the prevalence of autoimmune comorbidities in patients with metastatic melanoma was higher than that in patients with nonmetastatic melanoma and in the general population, and had increased substantially over time from 2004 to 2014.

In addition, for metastatic melanoma, those patients who were female, or who were located in South or North Central US regions, with bone or gastrointestinal metastasis, or those patients who had a higher comorbid disease burden were shown to have an increased likelihood of having autoimmune disorders.

These findings of increased prevalence of autoimmune comorbidities among patients with metastatic melanoma are particularly important given that some of the newer agents for treating metastatic melanoma (e.g., checkpoint inhibitors) are associated with a high incidence of severe immune-related AEs. Thus, autoimmune comorbidities in patients with metastatic melanoma should be taken into consideration when treatment decisions are made.

\section{Abbreviations}

AE: Adverse event; Cl: Confidence interval; ICD-9: International Classification of Diseases, Ninth Edition; OR: Odds ratio; RCC: Renal-cell carcinoma

\section{Acknowledgements}

Medical writing assistance was provided by ApotheCom Ltd., funded by Amgen Inc.

\section{Funding}

This study was funded by Amgen Inc.; employees of Amgen Inc. designed the study, performed analysis and interpretation of data, and writing of the manuscript.

\section{Availability of data and materials}

The data that support the findings of this study are available from Truven Health Analytics ${ }^{\text {TM }}$ but restrictions apply to the availability of these data, which were used under licence for the current study, and so are not publicly available. Data are however available from the authors upon reasonable request and with permission of Truven Health Analytics ${ }^{\text {TM }}$

\section{Authors' contributions}

QM contributed to the study design, analysis of the data and manuscript writing; MS contributed to the study design, analysis of the data and manuscript writing; ZZ contributed to the study design, analysis of the data and manuscript writing; ML contributed to the statistical analysis of the data and manuscript writing; NB contributed to the analysis of the data and manuscript writing; and BB contributed to the study design, analysis of the data and manuscript writing. All authors agree to take responsibility for the entire manuscript and have approved the final draft.

\section{Ethics approval and consent to participate}

This study used Truven MarketScan ${ }^{\oplus}$ administrative claims data. The data were de-identified and accessed in accordance with the Health Insurance Portability and Accountability Act of 1996; Institutional Review Board approval was not required for this study.

\section{Consent for publication}

Not applicable.

\section{Competing interests}

Qiufei Ma, Mark Shilkrut, Zhongyun Zhao, Nicolas Batty, and Beth Barber are currently employed by Amgen Inc. Minming Li is a PhD candidate at the University of Massachusetts, Amherst.

\section{Publisher's Note}

Springer Nature remains neutral with regard to jurisdictional claims in published maps and institutional affiliations.

\section{Author details}

${ }^{1}$ Department of Global Health Economics, Amgen Inc., One Amgen Center Drive, Thousand Oaks, CA 91320-1799, USA. ${ }^{2}$ Clinical Research Oncology/ Hematology, Amgen Inc., Thousand Oaks, CA, USA. ${ }^{3}$ Department of Biostatistics, University of Massachusetts at Amherst, Amherst, MA, USA.

Received: 11 August 2016 Accepted: 24 January 2018

Published online: 06 February 2018

\section{References}

1. American Cancer Society. Cancer Facts \& Figures 2015. http://www.cancer. org/acs/groups/content/@editorial/documents/document/acspc-044552.pdf. Accessed Jan 2016.

2. Garbe C, Peris K, Hauschild A, Saiag P, Middleton M, Spatz A, et al. Diagnosis and treatment of melanoma: European consensus-based interdisciplinary guideline. Eur J Cancer Oxf Engl. 2010;46:270-83.

3. National Comprehensive Cancer Network (NCCN): Clinical Practice Guidelines in Oncology (NCCN Guidelines ${ }^{\circledR}$ ); Melanoma Version 2.2016.

4. Balch CM, Gershenwald JE, Soong S, Thompson JF, Atkins MB, Byrd DR, et al. Final version of 2009 AJCC melanoma staging and classification. J Clin Oncol. 2009;27:6199-206.

5. Song X, Zhao Z, Barber B, Farr AM, Ivanov B, Novich M. Overall survival in patients with metastatic melanoma. Curr Med Res Opin. 2015;31:987-91.

6. Atkins MB. Cytokine-based therapy and biochemotherapy for advanced melanoma. Clin Cancer Res Off J Am Assoc Cancer Res. 2006;12(7 Pt 2): 2353s-8s.

7. Atkins MB, Hsu J, Lee S, Cohen Gl, Flaherty LE, Sosman JA, Sondak VK, Kirkwood JM. Phase III trial comparing concurrent biochemotherapy with cisplatin, vinblastine, dacarbazine, interleukin-2, and interferon alfa-2b with cisplatin, vinblastine, and dacarbazine alone in patients with metastatic malignant melanoma (e3695): a trial coordinated by the eastern cooperative oncology group. J Clin Oncol. 2008;26:5748-54.

8. Keilholz U, Goey SH, Punt CJ, Proebstle TM, Salzmann R, Scheibenbogen C, Schadendorf D, Liénard D, Enk A, Dummer R, Hantich B, Geueke AM, Eggermont AM. Interferon alfa-2a and interleukin-2 with or without cisplatin in metastatic melanoma: a randomized trial of the European Organization for Research and Treatment of cancer melanoma cooperative group. J Clin Oncol. 1997;15:2579-88

9. La-Beck NM, Jean GW, Huynh C, Alzghari SK, Lowe DB. Immune checkpoint inhibitors: new insights and current place in cancer therapy. Pharmacotherapy. 2015;35:963-76.

10. Davies H, Bignell GR, Cox C, Stephens P, Edkins S, Clegg S, et al. Mutations of the BRAF gene in human cancer. Nature. 2002;417:949-54.

11. John L, Cowey CL. The rapid emergence of novel therapeutics in advanced malignant melanoma. Dermatol Ther. 2015;5:151-69.

12. Wolchok JD, Hodi FS, Weber JS, Allison JP, Urba WJ, Robert C, et al. Development of ipilimumab: a novel immunotherapeutic approach for the treatment of advanced melanoma. Ann N Y Acad Sci. 2013;1291:1-13.

13. Kong Y-CM, Flynn JC. Opportunistic autoimmune disorders potentiated by immune-checkpoint inhibitors anti-CTLA-4 and anti-PD-1. Front Immunol. 2014;5:206.

14. Eggermont AM, Chiarion-Sileni V, Grob JJ, Dummer R, Wolchok JD, Schmidt $\mathrm{H}$, et al. Adjuvant ipilimumab versus placebo after complete resection of high-risk stage III melanoma (EORTC 18071): a randomised, double-blind, phase 3 trial. Lancet Oncol. 2015;16:522-30.

15. Ribas A, Puzanov I, Dummer R, Schadendorf D, Hamid O, Robert C, et al. Pembrolizumab versus investigator-choice chemotherapy for ipilimumabrefractory melanoma (KEYNOTE-002): a randomised, controlled, phase 2 trial. Lancet Oncol. 2015;16:908-18.

16. European Medicines Agency. Ipilimumab Summary of Product Characteristics. 2011. http://www.ema.europa.eu/docs/en_GB/document_ library/EPAR_-_Product_Information/human/002213/WC500109299.pdf. Accessed January 2015.

17. Food and Drug Administration. Ipilimumab Prescribing Information. 2015. http://www.accessdata.fda.gov/drugsatfda_docs/label/2015/125377s073lbl. pdf. Accessed January 2016. 
18. European Medicines Agency. Nivolumab Summary of Product Characteristics. 2015. http://www.ema.europa.eu/docs/en_GB/document library/EPAR_-_Product_Information/human/003840/WC500190648.pdf. Accessed January 2016.

19. Food and Drug Administration. Nivolumab Prescribing Information. 2015. http://www.accessdata.fda.gov/drugsatfda_docs/label/2015/125554s005lbl. pdf. Accessed January 2016.

20. European Medicines Agency. Pembrolizumab Summary of Product Characteristics. http://www.ema.europa.eu/docs/en_GB/document_library/ EPAR_-_Product_Information/human/003820/WC500190990.pdf. Accessed January 2016

21. Food and Drug Administration. Pembrolizumab Prescribing Information. 2015. http://www.accessdata.fda.gov/drugsatfda_docs/label/2015/ 125514s005lbl.pdf. Accessed January 2016.

22. European Medicines Agency. Summary of the risk management plan (RMP) for nivolumab. 2015. http://www.ema.europa.eu/docs/en_GB/document_ library/EPAR_-_Risk-management-plan_summary/human/003985/ WC500186052.pdf. Accessed January 2016.

23. European Medicines Agency. Summary of the risk management plan (RMP) for ipilimumab. 2011. http://www.ema.europa.eu/docs/en_GB/document_ library/EPAR___Public_assessment_report/human/002213/WC500109302.pdf. Accessed January 2016.

24. European Medicines Agency. EPAR; Summary of the risk management plan (RMP) for pembrolizumab. 2015. http://www.ema.europa.eu/docs/en_GB/ document_library/EPAR_-_Risk-management-plan_summary/human/ 003820/WC500187334.pdf. Accessed January 2016.

25. Hodi FS, O'Day SJ, McDermott DF, Weber RW, Sosman JA, Haanen JB, et al. Improved survival with ipilimumab in patients with metastatic melanoma. N Engl J Med. 2010;363:711-23.

26. Robert $C$, Long GV, Brady B, Dutriaux C, Maio M, Mortier $L$, et al. Nivolumab in previously untreated melanoma without BRAF mutation. N Engl J Med. 2015:372:320-30.

27. Robert C, Schachter J, Long GV, Arance A, Grob JJ, Mortier L, Daud A, Carlino MS, McNeil C, Lotem M, et al. KEYNOTE-006 investigators: Pembrolizumab versus ipilimumab in advanced melanoma. N Engl J Med. 2015;372:2521-32.

28. International Classification of Diseases, Ninth Revision, Clinical Modification ICD-9-CM. http://www.cdc.gov/nchs/icd/icd9cm.htm. Accessed January 2016.

29. American Autoimmune Related Diseases Association (AARDA) autoimmune related disease information. http://www.aarda.org/. Accessed January 2016

30. Cooper GS, Bynum MLK, Somers EC. Recent insights in the epidemiology of autoimmune diseases: improved prevalence estimates and understanding of clustering of diseases. J Autoimmun. 2009;33:197-207.

31. Eaton WW, Rose NR, Kalaydjian A, Pedersen MG, Mortensen PB. Epidemiology of autoimmune diseases in Denmark. J Autoimmun. 2007;29:1-9.

32. Jacobson DL, Gange SJ, Rose NR, Graham NM. Epidemiology and estimated population burden of selected autoimmune diseases in the United States. Clin Immunol Immunopathol. 1997:84:223-43.

33. Liu X, Ji J, Forsti A, Sundquist K, Sundquist J, Hemminki K. Autoimmune disease and subsequent urological cancer. J Urol. 2013;189:2262-8.

\section{Submit your next manuscript to BioMed Central and we will help you at every step:}

- We accept pre-submission inquiries

- Our selector tool helps you to find the most relevant journal

- We provide round the clock customer support

- Convenient online submission

- Thorough peer review

- Inclusion in PubMed and all major indexing services

- Maximum visibility for your research

Submit your manuscript at www.biomedcentral.com/submit 